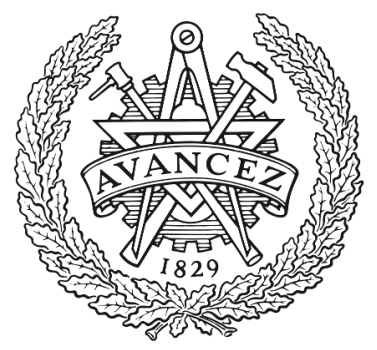

CHALMERS

UNIVERSITY OF TECHNOLOGY

\title{
Micromachined contactless pin-flange adapter for robust high-frequency measurements
}

Downloaded from: https://research.chalmers.se, 2023-04-26 11:47 UTC

Citation for the original published paper (version of record):

Rahiminejad, S., Pucci, E., Haasl, S. et al (2014). Micromachined contactless pin-flange adapter for robust high-frequency measurements. Journal of Micromechanics and Microengineering, 24(8): Art. no. 084004-. http://dx.doi.org/10.1088/0960-1317/24/8/084004

N.B. When citing this work, cite the original published paper. 


\title{
MICROMACHINED CONTACTLESS PIN-FLANGE ADAPTER FOR ROBUST HIGH-FREQUENCY MEASUREMENTS
}

\author{
S. Rahiminejad ${ }^{1}$, E. Pucci² ${ }^{2}$ S. Haasl ${ }^{3}$ and P. Enoksson ${ }^{1}$ \\ ${ }^{I}$ Chalmers University of Technology, Department of Microtechnology and Nanoscience, SE-412 96 \\ Gothenburg, Sweden \\ ${ }^{2}$ Chalmers University of Technology, Department of Signals and Systems, SE-412 96 Gothenburg, \\ Sweden \\ ${ }^{3}$ Royal Institute of Technology, SE-141 52 Stockholm, Sweden
}

\begin{abstract}
We present the first micromachined double-sided contactless WR03 pin-flange adapter for $220-325 \mathrm{GHz}$ based on gap waveguide technology. The pin-flange adapter is used to avoid leakage at the interface of two waveguides even when a gap between them is present and can be fitted onto any standard WR03 waveguide flange. Tolerance measurements were performed with gaps ranging from $30-100 \mu \mathrm{m}$. The performance of the micromachined pin flange has been compared to a milled pin flange, a choke flange and to standard waveguide connections. The micromachined pin flange is shown to have better performance than the standard connection and similar performance to the milled pin flange and choke flange. The benefits of micromachining over milling are the possibility to mass produce pin flanges and the better accuracy in the 2D design. Measurements were performed with and without screws fixing the flanges. The flanges have also been applied to measure two devices, a straight rectangular waveguide of 1.01 inch and on a ridge gap resonator. In all cases, the micromachined pin flange performed flawlessly while the standard flange experienced significant losses already at small gaps.
\end{abstract}

Keywords: GHz, High-frequency, MEMS, RF, Metamaterial, Gap Waveguide, Measurement adapters, Pin flange, Micromachining, Si 


\section{I - Introduction}

Microwave technology is a rapidly evolving field with a continuous drive towards higher frequencies. Together with the need for high frequency components, there is a need for fabrication technologies that can produce micro-scale devices. Due to their low losses, rectangular waveguides are the conventional choice for high-frequency applications. Micromachined rectangular waveguides are most commonly made out of Si [1-4]. Recently the use of SU8 for RF applications has become more common and there are also micromachined waveguides made out of SU8 [5,6]. Sammoura et al. reported a micromachined plastic waveguide for $95 \mathrm{GHz}$ [7]. The issue with rectangular waveguides is that they need solid, fully conductive walls with no gaps, which makes them difficult to assemble when reaching for higher frequencies. There are post-wall waveguides [8] also called SIW (Substrate Integrated Waveguides) [9] which do not need solid walls. However, they still need electrical contact between the posts and the bottom and top plate.

Gap waveguides, on the other hand, can operate with a gap up to a quarter of the wavelength. First introduced in 2009 by Kildal et al. [10], gap waveguides exist in three varieties: ridge, groove and microstrip [11]. The first experimentally tested gap waveguides constructed for $10-20 \mathrm{GHz}$ were presented in [12]. Various different gap waveguide applications have been presented since then, such as packaging of microstrip circuits [13], microstrip filters [14], groove gap based filters [15], an MMIC amplifier [16] and, most recently antennas [17]. Gap waveguides for higher frequencies have been micromachined and exists for $100 \mathrm{GHz}[18,19]$ and for $220-320 \mathrm{GHz}[20]$.

This gap waveguide technology is based on using a metamaterial realization of a magnetic conductor, together with an overlaying electric conductor, Fig. 1. The magnetic conductor is in this case realized by a bed-of-nails surface [21]. This is a surface with electrically conducting pins which, from a macroscopic point of view, works as an Artificial Magnetically Conductive (AMC) surface. The pins create an array of open circuits which in turn makes the tangential magnetic field zero at its surface. The tangential electric field on the other hand has a non-zero 


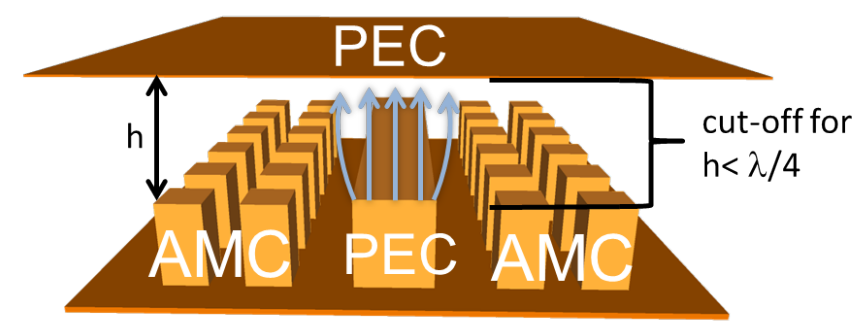

Figure 1: Illustration of a ridge gap waveguide. The ridge and the lid are PEC surfaces, where the wave can propagate between them, and the pin-surface realizes the AMC surface, prohibiting the wave from propagating anywhere outside the ridge.

value. Thus, we get the equivalent of a magnetically conducting surface. It is artificial for the reason that the pin surface has another electromagnetic property than the material it is made of. A perfect electrically conductive (PEC) surface has opposite characteristics: the tangential electric field is zero at the surface. When applying an electrically conducting lid above the AMC surface at a distance less than $\lambda / 4$, a stop band is created so that no waves can propagate in the gap between the two surfaces [22].

When measuring on high-frequency components, probes or rectangular waveguides are used. Rectangular waveguides have solid conducting walls and therefore have low losses within the waveguide. However, these need to be in good electrical contact with the measured object to avoid losses in the transition. This is achieved by screwing the flanges tightly to the object. However, if the surface is uneven or if anything, e.g. small particles or a deformed surface, is in the way and creates a gap, losses will increase. In [23] simulations show how sensitive a waveguide connection operating at $220-325 \mathrm{GHz}$ is to a gap of $20 \mu \mathrm{m}$, resulting in an increase of the return loss with over $20 \mathrm{~dB}$, compared to a perfect contact. Also, if the measured device is sensitive to hard and uneven pressure, screwing the waveguide tightly against the device can cause damage to it.

A challenge with the measurements on the first micromachined ridge gap resonator for $220-325 \mathrm{GHz}$, presented in [20], was to obtain a good electrical contact between the measured device and the measurement flange. A resonator does in theory not require strong 
coupling. However, in this case, the signal was too weak to be even read by the measurement equipment and a new solution was needed. Initially, to solve this, a standard WR03 waveguide flange was modified to have a $\lambda / 4$ ring around the opening, i.e. a so-called choke to damp the leakage caused by the gap (see fig. 2). The choke ring works as an open circuit around the opening. Because of this, the waves will not propagate in any direction away from the opening [24]. The choke flange will work even with a small gap between the flange and the measurement object. Inspired by this technology and with the idea of avoiding different sets of waveguides during measurement, a contactless waveguide measurement pin-flange adapter was precision milled. The adapter is designed so it can be fitted on any WR standard flange and does not require electrical contact. Based on the gap waveguide theory, the stop band between the two surfaces exists as long as the gap between them is smaller than $\lambda / 4$. In [25], similar work has been presented with photonic crystal joints with a loss of $0.5 \mathrm{~dB} / \mathrm{m}$ at $10.5 \mathrm{GHz}$ with a $50 \mu \mathrm{m}$ gap, however, in [26], the loss extracted from a short-circuited ridge gap resonator at $13.3 \mathrm{GHz}$ with a $3 \mathrm{~mm}$ air gap was $0.254 \mathrm{~dB} / \mathrm{m}$. Simulations and theory of our pin-flange adapter were presented in [23]. Earlier simulations have been made of similar designs to the pin flange and choke [27] but nothing was ever fabricated or measured upon.

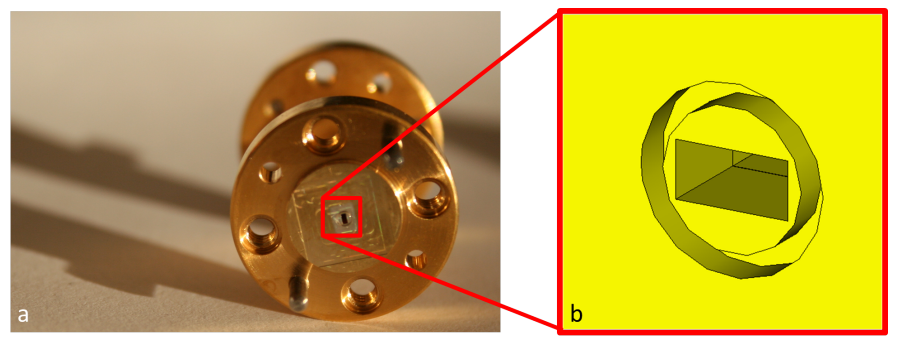

Figure 2: a)WR03 standard flange modified with $a$ b) choke ring close to the opening

Compared to microfabrication, milling of structures is a time-demanding process with limited precision. In this paper, we present and discuss, in addition to the milled prototypes, a fully micromachined pin-flange adapter. These are compared with standard flanges and choke flanges, and tolerance to gaps measurements are performed. Furthermore, we present measurement results of the use of flanges with a straight rectangular $25.425 \mathrm{~mm}$ waveguide and a ridge-gap resonator. 
The first fully micromachined gap waveguide device, a pin-flange adapter, is presented here. In this paper, we focus on the realization and evaluation by measurements of the micromachined pin-flange adapter, and on comparing the micromachined pin-flange adapter to a milled prototype and to standard connections. Finally, the flanges are used for measuring two devices, a straight rectangular waveguide of 1.01 inch and a ridge gap resonator.

\section{II - Design}

The simulated design presented in [23] is based on the standard WR03 measurement flange (Electronic Industries Alliance designation standard). Two rows of pins surround the rectangular waveguide opening to create the AMC surface. The AMC surface creates a parallel-plate cut-off region within the air gap that is between the pin flange and the device under test, provided the opposing surface is electrically conducting (Fig. 3). A circular wall with the same height as the surrounding pins surrounds the rectangular waveguide opening, Fig. 4a. The wall has the purpose of avoiding reflections that can occur between the waveguide and the device to be measured. The wall needs to be a quarter wavelength wide radially from its widest side to act as an impedance transformer which transforms an open circuit to a short circuit. The pins are quadratic with a width of $167 \mu \mathrm{m}$ and height of $277 \mu \mathrm{m}$.

The simulation of creating a parallel-plate cut-off region is shown in Fig. 5a, where the dispersion diagram has been plotted with CST Microwaves Studio, for an infinite periodic unit cell of a metal pin, shown in Fig. 5b. The length of the pin is $d=277 \mu m$, the width is $a=167 \mu \mathrm{m}$ and the distance between the pins is $p=194 \mu \mathrm{m}$. The pin-flange adapter works provided the opposing surface is electrically conducting. The air gap, Fig. 3, between the pin and the upper metal plate must be smaller than $\lambda / 4$ and is chosen to be $h=56 \mu \mathrm{m}$. The simulated dispersion diagram shows that a stop band region in which the modes cannot propagate, is created from $180 \mathrm{GHz}$ to $400 \mathrm{GHz}$, see Fig. 5a. 


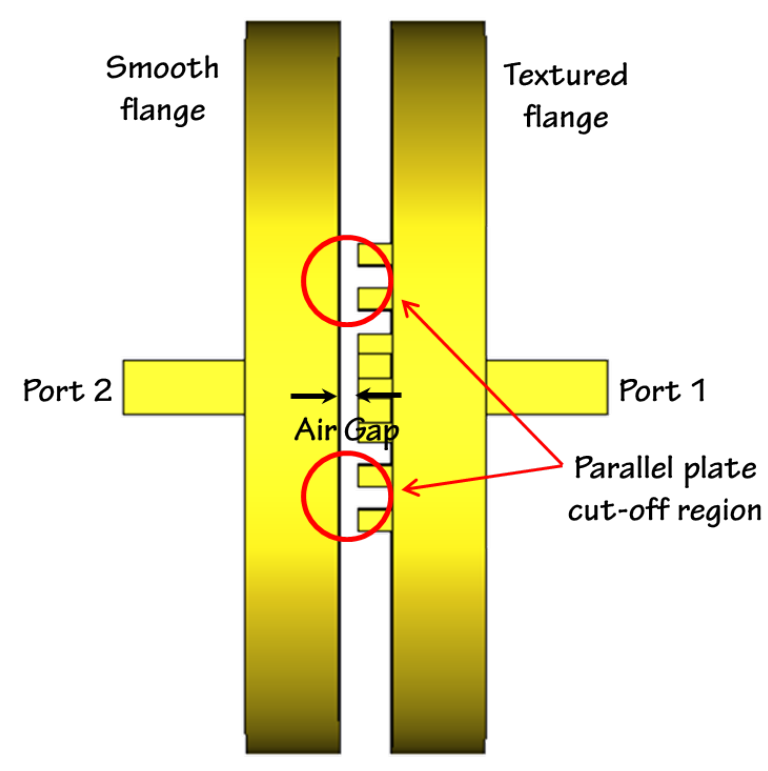

Figure 3: A pin flange (to the right) facing a regular flange (to the left) with an air gap between them.

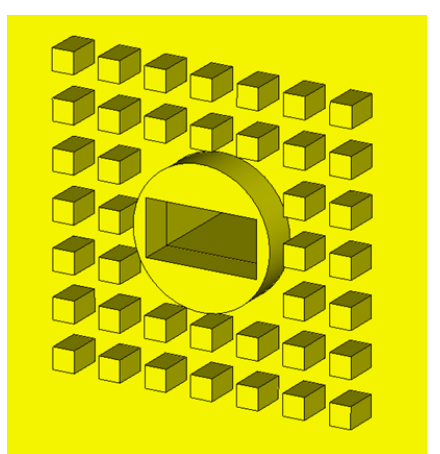

(a)

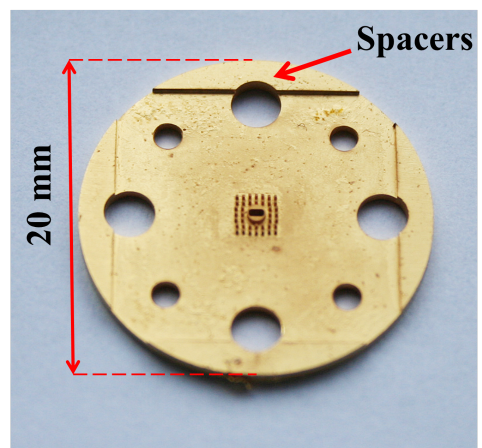

(b)

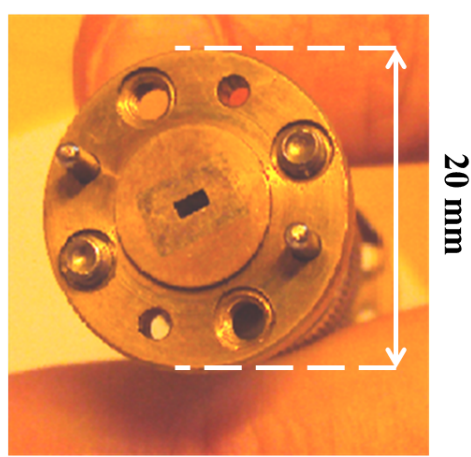

(c)

Figure 4: (a) A design of the proposed pin-flange surface around the waveguide opening. (b) The pinflange adapter prototype. (c) Standard WRO3 measurement flange opening.

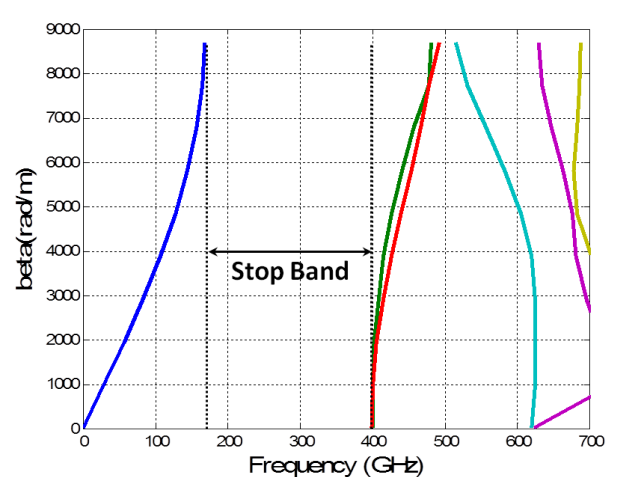

(a)
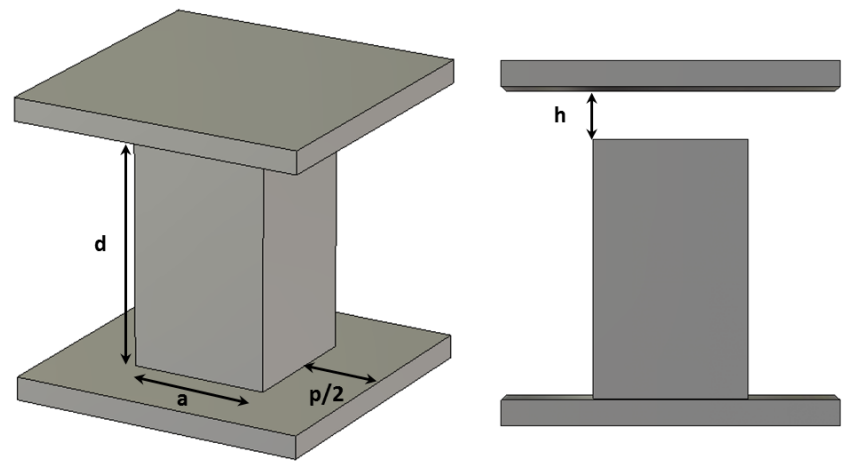

(b)

Figure 5: (a) Dispersion diagram displaying the stop band between $180 \mathrm{GHz}$ and $400 \mathrm{GHz}$.(b) The metal pin unit cell used for the simulations. 
A prototype was milled in brass and then gold coated, [28]. This design also has two rows of pins with the same dimensions as the simulated design mentioned above. The difference is that four spacers were built in to realize the simulated $56 \mu \mathrm{m}$ gap, Fig. $4 \mathrm{~b}$. The prototype has a disc shape. There are four big holes for the flange screw and four smaller holes for the guiding pins (Fig. 4c) on the flange. They are placed so as to match the WR03 waveguide standard such that the adapter can be fit onto any WR03 flange, providing full compatibility with existing equipment Fig. 4b.

A choke flange was also designed based on simulations for the same frequencies as the pin flange. The choke has a ring with a depth of $277 \mu m$ (the same as the height of the pins) around the opening. The radius of the ring is $534 \mu \mathrm{m}$ and the width is $167 \mu \mathrm{m}$. The choke flange has also four spacers of $56 \mu \mathrm{m}$ to be able to be compared to the pin flange.

In this paper, a micromachined version of the pin flange has been fabricated. The number of rows surrounding the pins has been increased to nine rows in each direction. This results in better electromagnetic properties as every row of pins reduces the wave with $20 \mathrm{~dB}$. As opposed to the case of milling, where this would cause a significant increase of fabrication time, the micromachined fabrication is actually reduced as the total etched area is decreased.

\section{III - Fabrication}

\section{A. Milled prototypes}

For the pin-flange adapter and the choke to work on both sides, a double-sided pin-flange adapter and a double-sided choke flange were fabricated by milling (KERN Evo). The prototypes were milled into a $1 \mathrm{~mm}$ thick brass disc to give the same thickness as the intended micromachined version and then electroplated with gold. The pin surface was milled on both

sides, leaving a thin membrane in the middle of the brass disc. The gold layer was $1.5 \mu \mathrm{m}$ thick to assure conductivity at the frequency range $220-325 \mathrm{GHz}$. To be able to manufacture it by milling, the design had to be adapted to the dimensional limit of the mill. The distance 
between the pins on the side of the waveguide opening was designed to be optimally $105 \mu \mathrm{m}$. The micro end mill had a diameter of $150 \mu \mathrm{m}$ with a cut depth of maximum $300 \mu \mathrm{m}$ thus the design had to be adapted. The number of pins were also limited to two rows, to limit the milling time. The prototype is shown in Fig. 4 b.

An overview of micro end mills from 20 companies represented at [29] showed that the best state of the art micro end mill that is capable of milling down to at least $277 \mu \mathrm{m}$ had a minimum diameter of $127 \mu \mathrm{m}$ and could be found from both Niagara cutters and Brubaker Tool. Micro end mills are limited by their diameter versus their cut depth, i.e. there are micro end mills with a smaller diameter that could give a higher resolution but the cut depth would be too small four this application. The limitation of micro end mills can be overcome by micromachining which can give a better resolution and higher aspect ratio.

\section{B. The micromachined pin-flange}

A micromachined double sided pin-flange was also fabricated with the optimum spacing of $105 \mu \mathrm{m}$ and nine rows of pins. The process plan can be seen in Fig. 6. A 6" Si wafer with a thickness of $540 \mu \mathrm{m}$ was sputtered with a $0.5 \mu \mathrm{m}$ Al layer on the front side, Fig. 6a. The Al layer was patterned with mask 1 using AZ4562 photoresist and then wet etched. The wafer was then stripped from the photoresist leaving only the Al pattern. Another layer of AZ4562 was spun on top of the Al layer on the front side at $3000 \mathrm{rpm}$, resulting in a thickness of about $6 \mu \mathrm{m}$. The photoresist was patterned with mask 2, Fig. $6 \mathrm{~b}$. The photoresist layer and the Al layer were used as hard masks during Inductively Coupled Plasma Deep Reactive-Ion Etching (ICP DRIE). The resist has a selectivity of 65:1 to Si. ICP DRIE was used to etch the holes and the waveguide opening down to $270 \mu \mathrm{m}$. All the ICP DRIE was done from the front side of the wafer, with an the average etch rate of $3.5 \mu \mathrm{m} / \mathrm{min}$. The photoresist was stripped from the wafer (Fig. 6c), exposing the Al pattern. The back side of the wafer was sputtered with Al to obtain a $0.5 \mu \mathrm{m}$ thick layer. The $\mathrm{Al}$ on the back side was used as a stop layer so that the waveguide opening and the holes could be etched all the way through the wafer (Fig. 6d) and then be stopped by the Al. The pins were also defined with this second ICP DRIE step as the 
holes reached the Al stop layer. The Al was then removed with $\mathrm{Al}$ wet etch (Fig. 8a and b) and the wafer diced. Two pin-flange halves were bonded back to back using an adhesive bonding (ethyl cyanoacrylate), Fig. 6e and 8c. The now double-sided pin flange was sputtered with a seed layer of Ti/Au $(50 / 200 \mathrm{~nm})$ with deposition rate of $1.1 \mathrm{~nm} / \mathrm{sec}$ respectively $1.2 \mathrm{~nm} / \mathrm{sec}$. The pin flange was later electroplated by immersion into Neutronex 309 gold plating solution. The solution had been heated up to $57^{\circ} \mathrm{C}$ and a platinum net was immersed into the solution and connected to the anode, while the pin flange was connected to the cathode. A current of $24 \mathrm{~mA}$ and a voltage of $0.6 \mathrm{~V}$ was applied for $15 \mathrm{~min}$ to obtain a gold layer with a thickness of $1.8 \mu \mathrm{m}$ (with an average deposition rate of $0.12 \mu \mathrm{m} / \mathrm{min}$ ) to assure conductivity at these frequencies, Fig. $6 \mathrm{f}$ and $8 \mathrm{~d}$. The rule of thumb used here was that the conductive layer needs to be five times thicker than the skin depth at the chosen frequencies, in this case it is more than 10 times thicker.
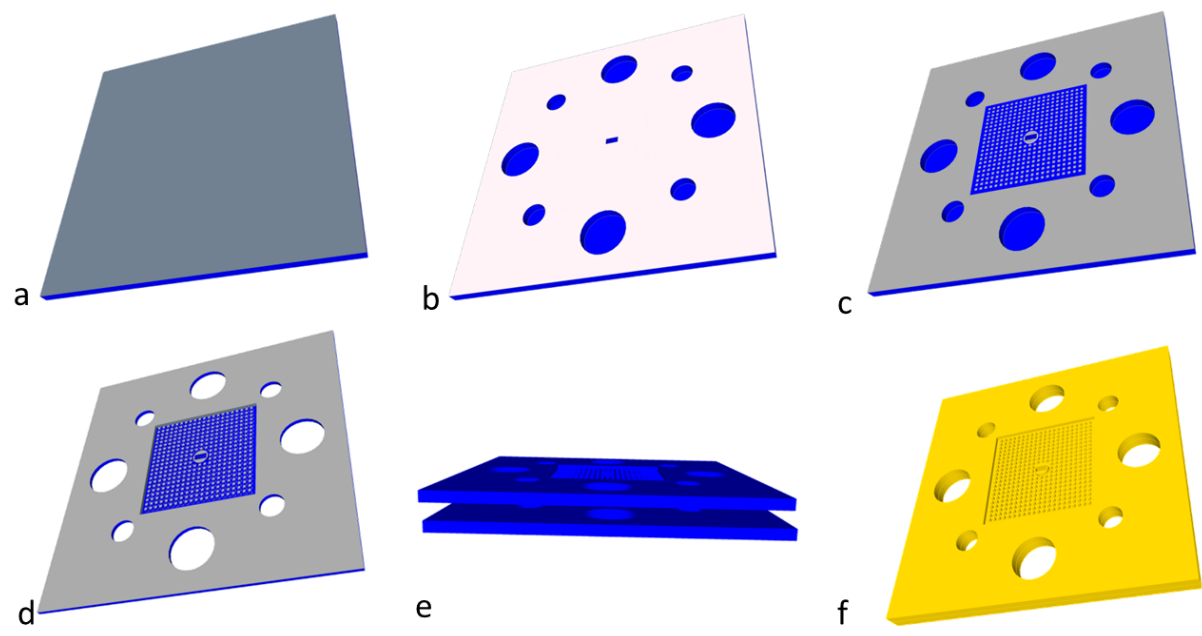

Figure 6: Process diagram, blue: Si, grey: Al, pink: photoresist, yellow: gold.

The process was inspired by the process in [20] where the pins were also $167 \mu \mathrm{m}$ wide, $277 \mu m$ high and $\mathrm{Al}$ was used as a hard mask. The pins fabricated with this process reduced in size by $2 \mu \mathrm{m}$ from the mask design i.e. after patterning the photoresist, wet etching of $\mathrm{Al}$ hard mask and ICP DRIE of the pins. This reduced size has a negligible effect on the performance of the structures. A microscope image of the pin-flange surface can be seen in Fig. 7, where the square shape of the pins after fabrication can be clearly seen. 


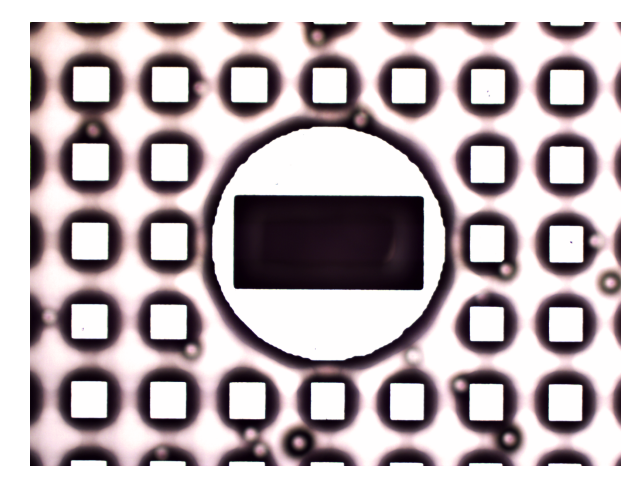

Figure 7: Microscope image with 5x zoom of the micromachined pin flange.

This process only needed two ICP DRIE steps and could be fabricated more easily and scaled up at a lower cost compared to the milled version, that was done with state of the art equipment. The reason is that the cost per device is less for a micromachined pin flange due to batch processing, as 12 double sided pin flanges are made on each wafer, compared to a state of the art, high-precision milled flange that can only be made one at a time. The time to micromachine one batch of pin flanges is far less than the time it takes to mill the same number one by one.

\section{$864 \mu \mathrm{m} \times 432 \mu \mathrm{m}$ waveguide opening}

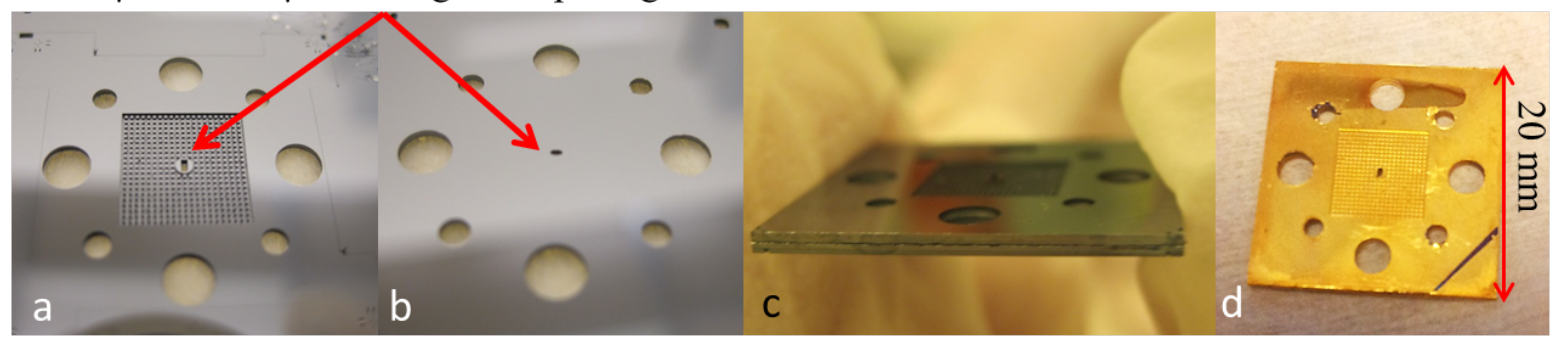

Figure 8: a) Front side view of the wafer after etching through the wafers. $b$ ) Back side view of the wafer after etching through the wafer. c) Side view of the two bonded pin-flange sides. d) Fully fabricated pin flange after Au-deposition. 


\section{IV - Measurements}

The measurements presented in this paper were done using two different setups.

\section{A. Measurement Setups}

Measurement setup 1, the setup seen in Fig. 9, where (a) is a Network Analyzer (Agilent N5250C) connected to (b), a millimeter-wave controller (Agilent N5260A). The millimeter-wave controller is coupled to the two OML extenders constructed for $220 \mathrm{GHz}-325 \mathrm{GHz}$ (c) where WR03 flanges (d) are connected to each side of the device under test. Between the WR03 flange and the support package (e), the pin-flange adapter is placed. The support package (e) in this figure can be replaced with any measurement object. This setup was used for all measurements where the built-in spacers of $56 \mu \mathrm{m}$ were used.
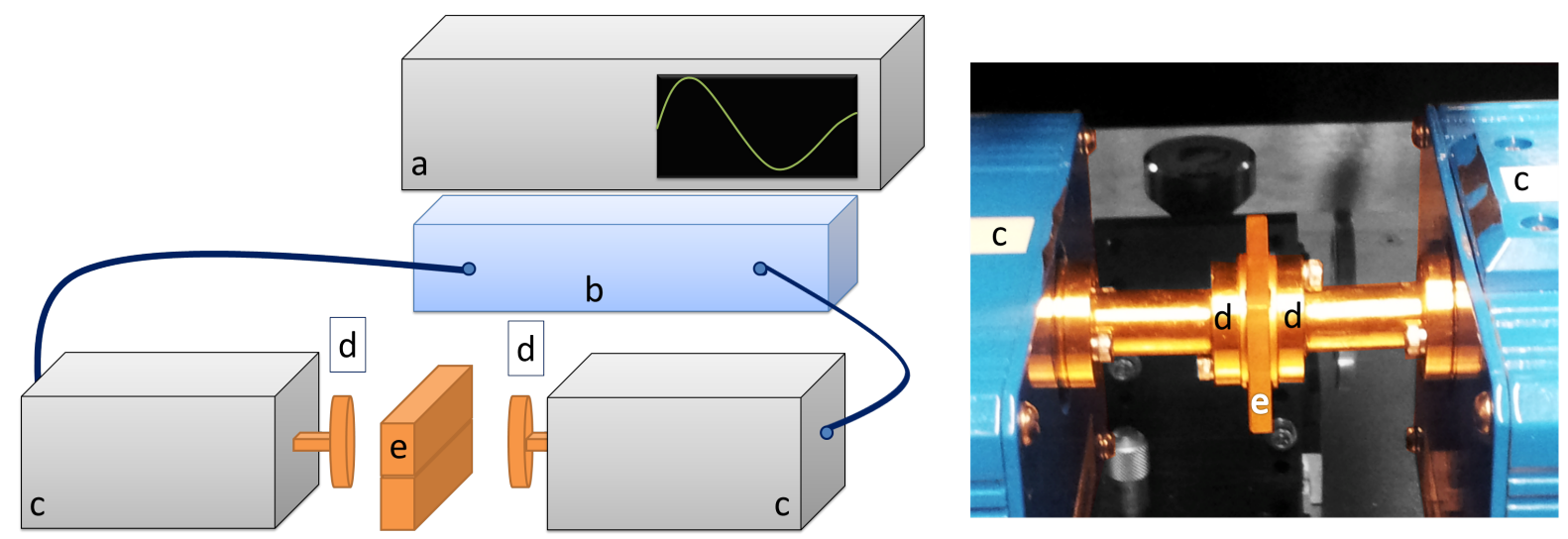

Figure 9: Measurement setup with a photo of the resonator being measured with the pin-flange adapters. a) The network analyzer (Agilent N5250C). b) The millimeter-wave controller (Agilent N5260A). c) OML extender. d) WR03 flange. e) Support package for the pin-flange adapter.

Measurement setup 2 was a similar second measurement setup, except that now a 4-port PNA N5222AS was used instead. The WR03 flanges (Fig. 9d) on the OML extenders in Fig. 9c were also replaced with WR03 flanges with a surface as in Fig. 4c where the built-in $56 \mu \mathrm{m}$ spacers (seen in Fig. 4b) on the milled prototypes are of no use. The air gap was then instead realized by inserting feeler gauges of different thicknesses as spacers, see Fig. 10. In this measurement setup, the gap is thus variable by using feeler gauges of different thicknesses. 
The setup is very sensitive, and it took an average of 10 calibration tries, to provide a sufficient calibration.

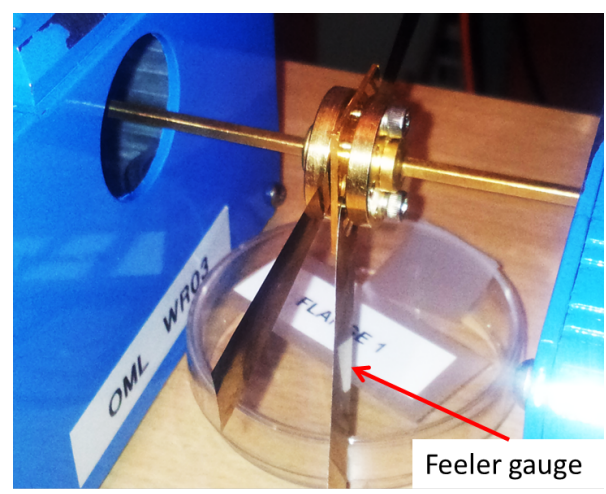

Figure 10: Measurement setup with the micromachined pin flange and feeler gauges as spacers.

\section{B. Flange Measurements}

These measurements were performed with measurement setup 1, to test and compare the milled double-sided pin-flange adapter with the milled double-sided choke flange and standard WR03 waveguide. Three types of setups were measured, shown in Fig. 12. Fig. 12a shows two standard WR03 flanges connected to a thin waveguide of $1 \mathrm{~mm}$ (Fig. 11a). Fig. 12b shows two standard flanges connected to the double-sided choke flange (Fig. 11b). The last setup in Fig. 12c shows the two standard WR03 flanges connected to the double-sided pin flange (Fig. 11c). The setup in Fig. 12c is used both for the milled brass prototype pin flange and the micromachined silicon pin flange (Fig. 8). The micromachined pin flange, however, was measured upon with measurement setup 2 .

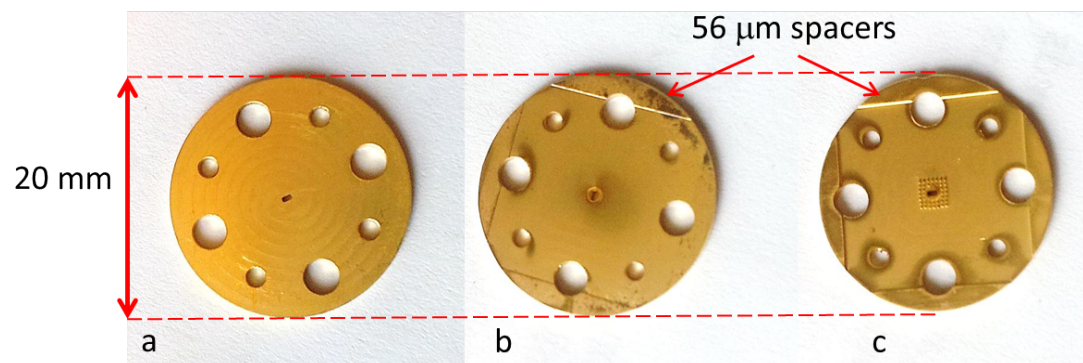

Figure 11: a) The $1 \mathrm{~mm}$ waveguide disc, b) the milled choke flange, c) the milled pin-flange. 


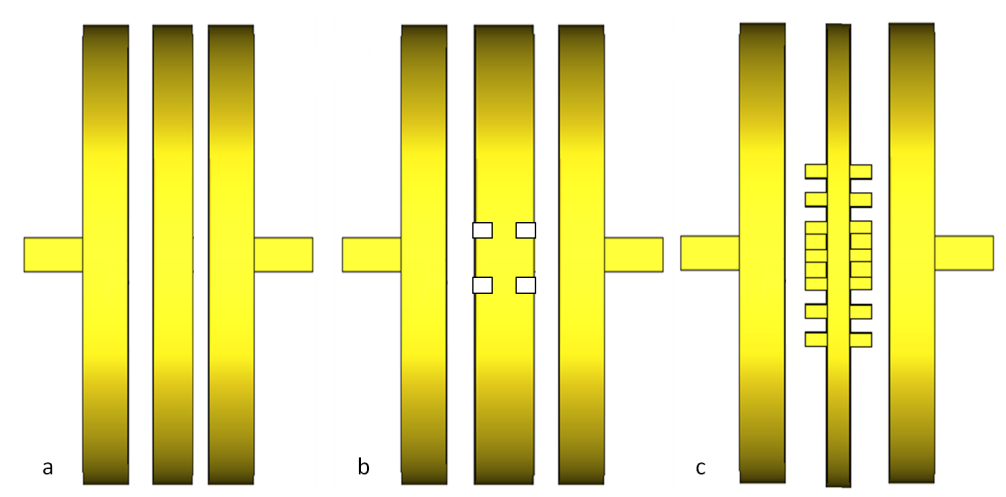

Figure 12: Measurement setup for comparing the different flanges. (a) Measurement setup for the standard WR03 flange, (b) measurement setup for the double-sided choke and (c) the measurement setup for the double-sided pin flange. (Spacers not shown in the figure)

\section{Tolerance to gap measurements}

The micromachined pin flange has no built-in gap and can therefore be measured with several different gaps by using feeler gauges of different thickness to investigate the sensitivity of different gap sizes. These measurements were done using measurement setup 2. Two feeler gauges of the same thickness were placed on each side of the micromachined pin flange as seen in Fig. 10. The used thicknesses were $30 \mu \mathrm{m}, 40 \mu \mathrm{m}, 50 \mu \mathrm{m}, 60 \mu \mathrm{m}$ and $100 \mu \mathrm{m}$. These measurements were done with screws fitted and tightened to assure the intended gap.

\section{Measurements on a straight rectangular waveguide}

To evaluate the losses more clearly, measurements were done on a straight rectangular waveguide with a length of $25.425 \mathrm{~mm}$. Three cases were measured: first, the waveguide was characterized using the standard WR03 ports at each side without anything in between, compare to Fig. 13 with the shown pin flanges removed. Second, the measurements were done with a milled double-sided choke flange (Fig. 11b) on each side of the straight rectangular waveguide, between the waveguide and the WR03 ports, similar to Fig. 13 but with the pin flanges shown replaced by choke flanges. Third, the same setup as the previous but with milled double-sided pin flanges (Fig. 11c) on both sides, as shown in Fig. 13. 


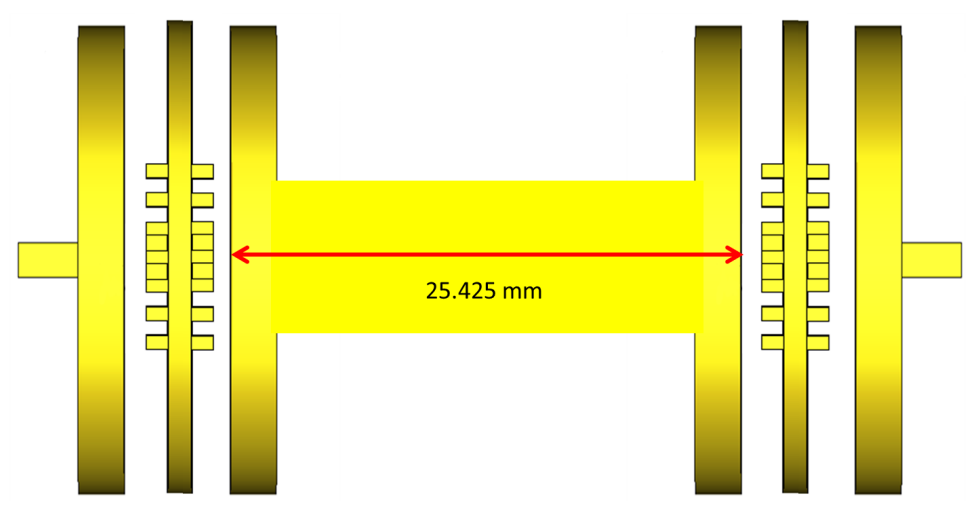

Figure 13: Measurement setup for comparing the straight rectangular waveguide with pin flanges between the waveguide and the measurement flanges on both sides. (Spacers not shown in the figure)

\section{E. Measurements on a resonator}

The challenge that inspired the development of the pin-flange adapter was the measurement on the ridge gap resonator for $220-325 \mathrm{GHz}$ [20], where leakage at the flanges was a problem. Therefore, the pin flange was compared with the other flanges also when measuring on this resonator. Three types of measurements were performed on the fabricated gap waveguide resonator according to the setup in Fig. 9, where the resonator is placed in the support package (e). These measurements were performed with measurement setup 1. In the first case, the resonator was measured with regular WR03 flanges. In the second case, the resonator was measured with in-house milled choke flanges (Fig. 11b) at both ends of the resonator. The third measurement was with the pin-flange adapters at both ends, with the pin surface facing the resonator. All three measurements were performed on a ridge-gap-waveguide resonator with a single pin row as presented in [20].

\section{V - Results and Discussion}

\section{A. Simulated data}

Simulation results are presented in Fig. 14 for the setup shown in Fig. 12c. The operation frequency chosen is the same as the one of the waveguide WR03, i.e. $220-325 \mathrm{GHz}$. The pin flange is aligned to a standard smooth flange, with an air gap of $56 \mu \mathrm{m}$ between them. Results 
show the simulated reflection coefficient (S11) from 'Port 1' and simulated the transmission coefficient (S21) between 'Port 1' and 'Port 2'. Simulation results shows S11 below $-20 d B$ up to $300 \mathrm{GHz}$ and below $-10 d B$ within the whole frequency range. The pin flange has already been compared by simulations with the known choke flange, predicting similar performances [23]. The pins has more degrees of freedom in the design and it is an isotropic surface thus working on both polarizations as opposed to the choke flange. The simulation is here intended to show the general behaviour of the pin flange but does not constitute the focus of this article.

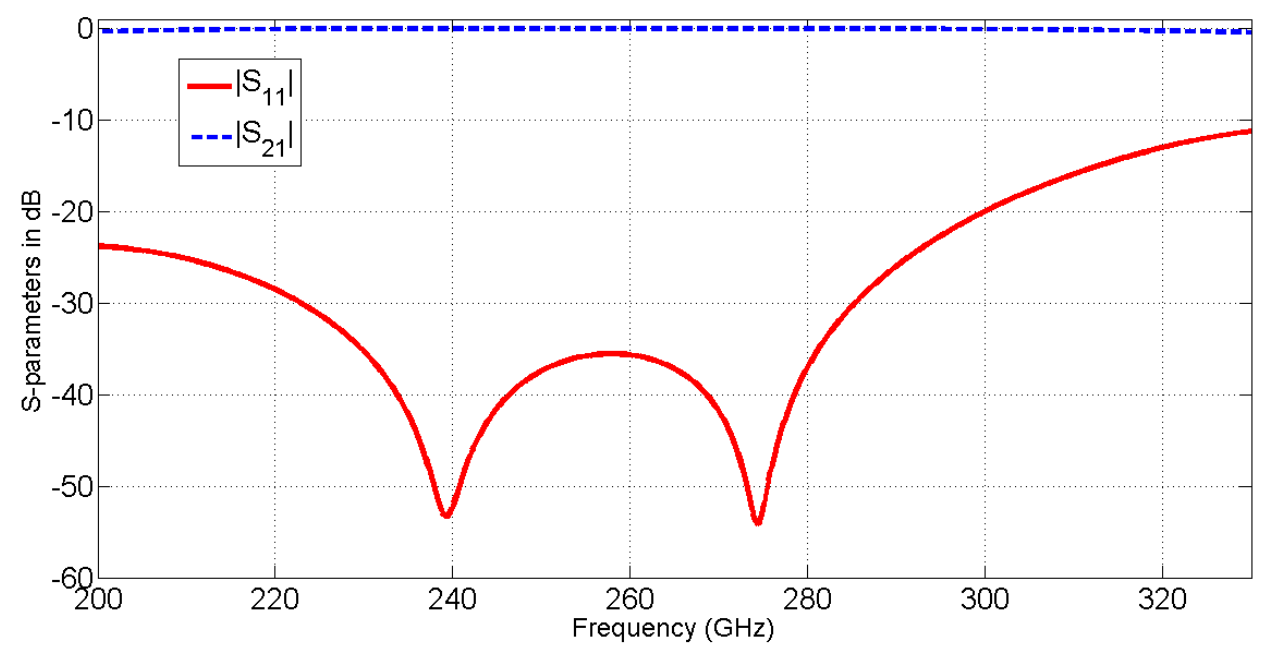

Figure 14: Simulation of standard waveguides connected to a double-sided pin-flange adapter as shown in Fig. $12 c$

B. Comparison between double-sided pin flange, standard flanges and choke flange with and without fixing screws.

In Fig. 15, measurements from the three setups shown in Fig. 12 are shown. Here, the double-sided choke and the double-sided pin flange have a $56 \mu \mathrm{m}$ gap between them and the measurement flanges. In all cases, the flanges are fitted with screws tightly pulling the transitions together. When looking at S21, it is shown that the transmission is lower for the standard waveguide connection, which has no gap between it and the measurement flanges, than for the double-sided pin and choke flange. S11 is quite similar for the double-sided pin flange and the double-sided choke flange. Even though the reflection (S11) is low for the 
standard waveguide, so is the transmission (S21), indicating losses in the form of leakage.

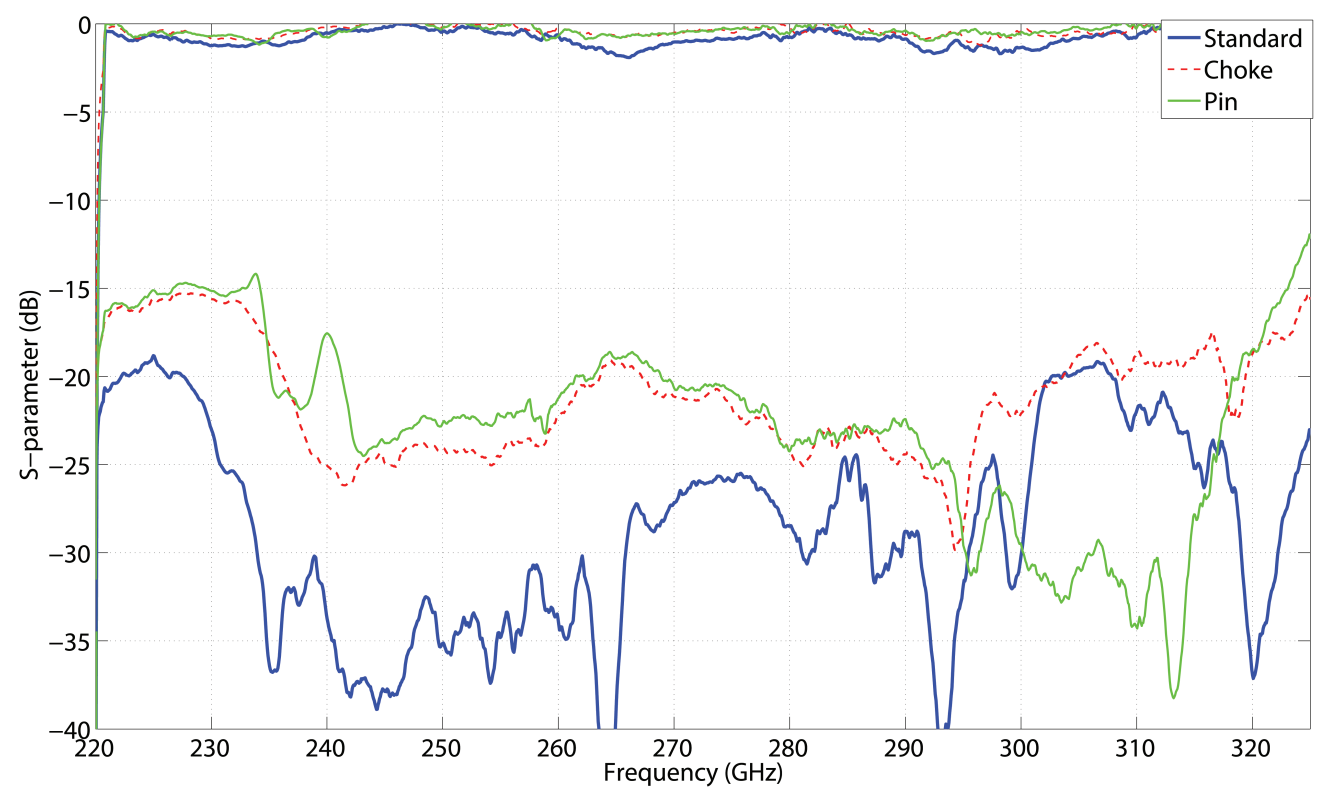

Figure 15: Measured S11 and S21 of the setup in Fig. 12, double sided pin-flange adapter (green thin line), double-sided choke (red dashed line) and the standard flanges (blue solid line).

The same measurements were performed again, with the exception that they were done without any screws keeping them tightly together. The measurement flanges were just pressed towards the double-sided pin and choke flanges. Fig. 16 shows that the S11 of the standard flange is higher than the S11 of both the double-sided pin and choke flange. The losses when measuring with the standard waveguide are more clear here where both the reflection (S11) is high and the transmission (S21) is distinctly lower than both the pin flange and the choke flange. Even though S11 for the double-sided pin flange is higher than for the double-sided choke flange, S21 for both flanges are comparable. These measurements show the robustness and tolerance to gaps of the pin-flange adapter compared to standard flanges.

\section{Tolerance to gap measurement results}

Fig. 17 shows the results of the tolerance measurement with different specific introduced gaps, explained in section IV.C. The transmission for almost all cases is similar except for the case 


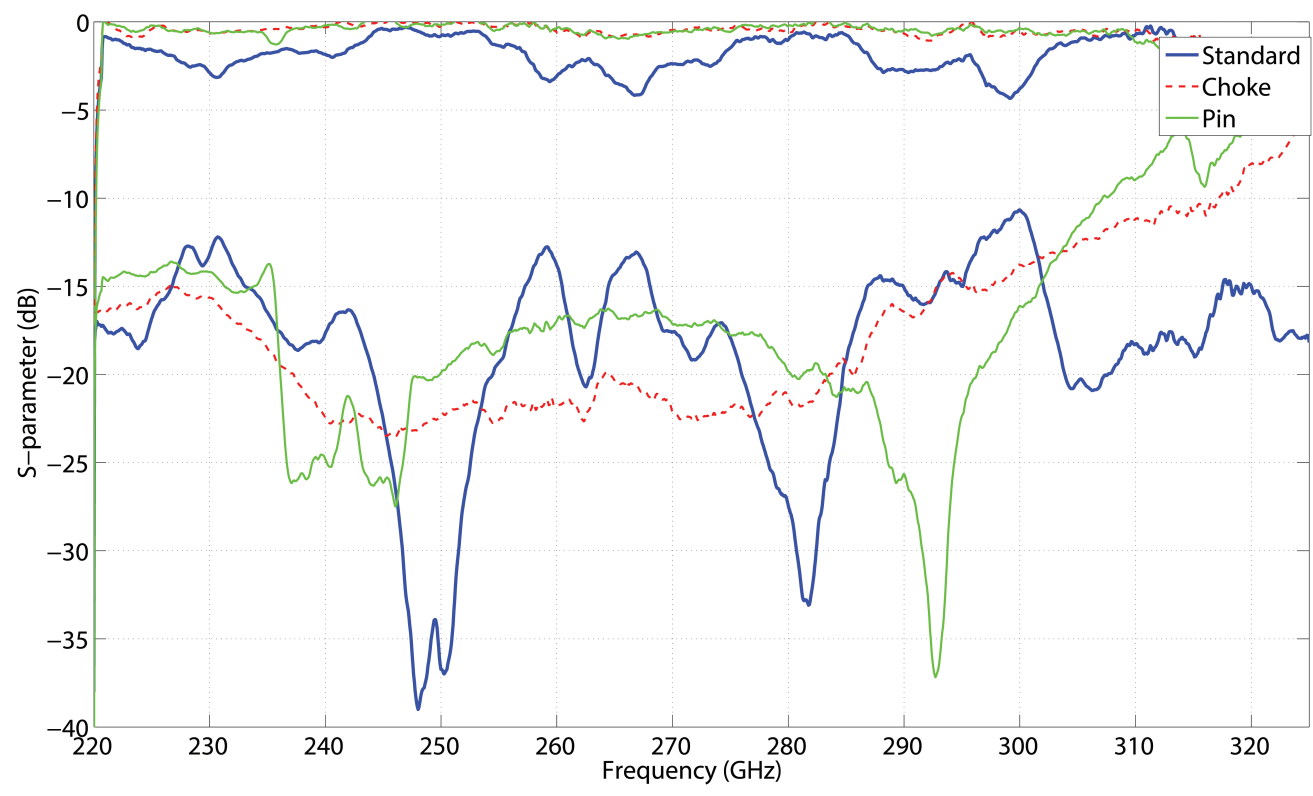

Figure 16: Measured S11 and S21 of the setup in Fig. 12, manually pushed together, without any screws attaching the flanges together. Double-sided pin-flange adapter (green thin line), double-sided choke (red dashed line) and the standard flanges (blue solid line).

with a $100 \mu \mathrm{m}$ gap which is lower due to the higher S11. The S11 for the case with a $40 \mu \mathrm{m}$ gap is the lowest (below $-20 \mathrm{~dB}$ ) from $240-325 \mathrm{GHz}$. The stop band seems to be shifted towards higher frequencies compared to simulations, and is optimal for a $40 \mu \mathrm{m}$ gap instead of for $56 \mu \mathrm{m}$ which were used in the simulation. This could be due to the height of the pins which is different than the target one. The ICP DRIE of the pins gives a height difference of $\pm 5 \%$ over a 6" wafer. For gaps from $30 \mu \mathrm{m}$ to $60 \mu \mathrm{m}$, the $\mathrm{S} 11$ is below $-15 \mathrm{~dB}$ from $240 \mathrm{GHz}$ upward. The stop band for a $100 \mu \mathrm{m}$ gap is narrower than for the other gaps: below $-20 \mathrm{~dB}$ between $244-289 \mathrm{GHz}$, thus even for such a relative large gap, the pin flange performs well.

D. Comparison of the double-sided micromachined pin flange with the milled pin flange, standard flanges and the choke flange

The micromachined pin flange was also compared to the prototype milled pin flange, the choke flange and the standard waveguide connection (as shown in Fig. 12). The results can be seen in Fig. 18. All devices had a gap of $50 \mu \mathrm{m}$ that was obtained using feeler gauges as in 


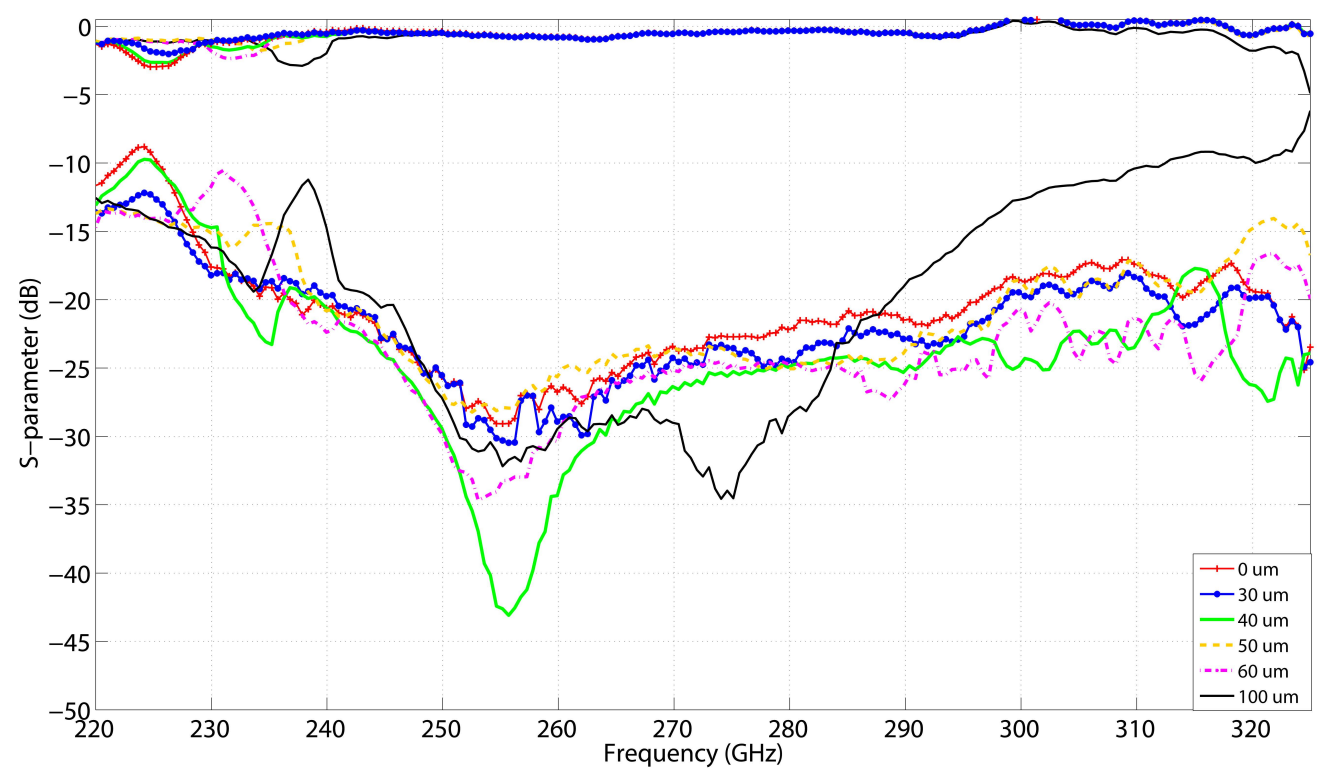

Figure 17: Measurements done on the micromachined pin flange with different gaps (30 $\mu \mathrm{m}, 40 \mu \mathrm{m}$, $50 \mu \mathrm{m}, 60 \mu \mathrm{m}$ and $100 \mu \mathrm{m})$.

Fig. 10. The flanges were fixed with screws to be sure of the $50 \mu m$ gap. S21 is comparable for the micromachined pin flange, the milled pin flange and the choke flange, however it is clearly lower for the standard waveguide. It is seen that the pin flange performs much better in this test than the standard flange. S11 for the standard waveguide connection is below $-10 d B$ over the entire frequency range. The $\mathrm{S} 11$ for the micromachined pin flange is below $-20 d B$ from $240 \mathrm{GHz}$ to $300 \mathrm{GHz}$ and the milled pin flange is below $-20 \mathrm{~dB}$ from $235 \mathrm{GHz}$ up to $295 \mathrm{GHz}$.

Mechanically, the micromachined pin flange, furthermore, is remarkably robust. The micromachined pin flange was mounted and dismounted more than 40 times without any detectable damage.

E. Comparison of the pin flanges with standard flanges and choke flanges connected to a straight $25.425 \mathrm{~mm}$ long rectangular waveguide

Fig. 19 shows measurements performed with a standard straight rectangular waveguide with a length of 1.01 inch i.e. $25.425 \mathrm{~mm}$. The pin flange and the choke have a $56 \mu \mathrm{m}$ gap between 


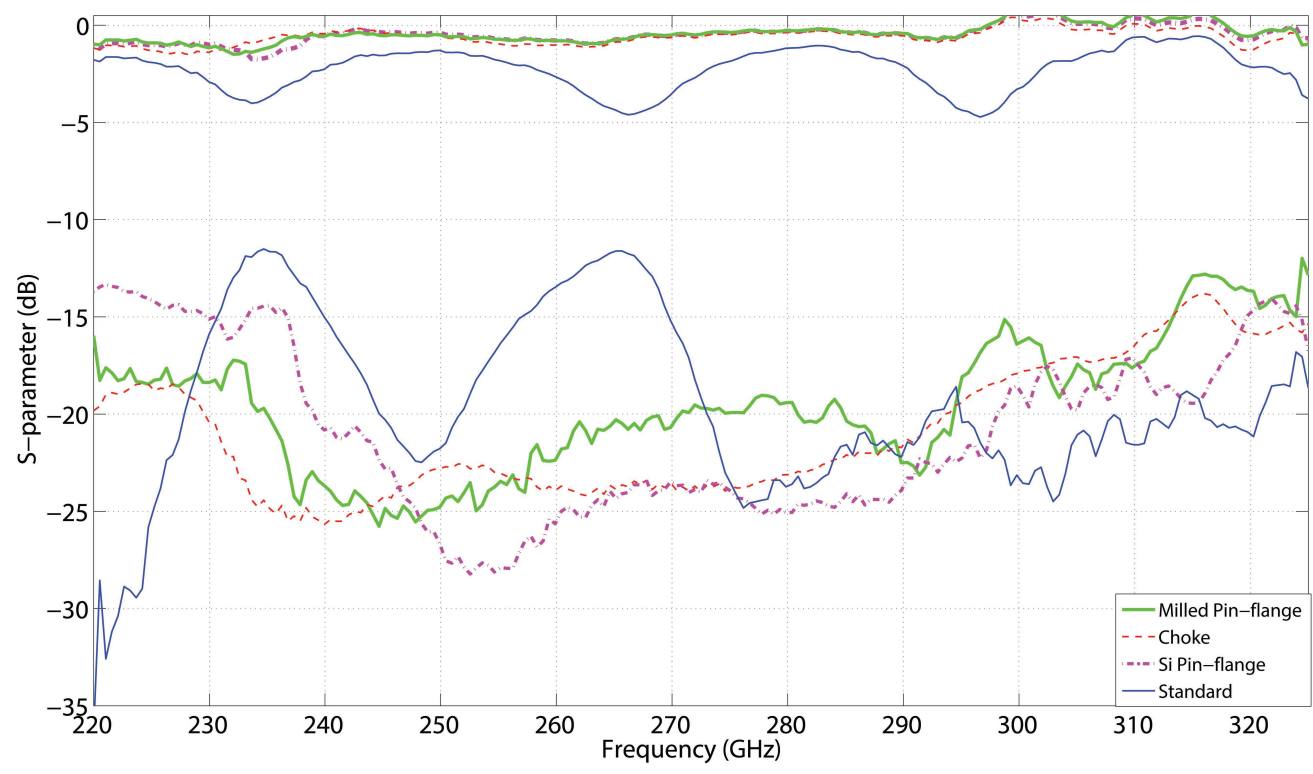

Figure 18: Measurements on the milled pin flange (green solid line), the choke (red dashed line), micromachined pin flange (purple dashed dot line) and standard waveguide disc (blue solid line), all with a $50 \mu \mathrm{m}$.

them and the straight rectangular waveguide. All flanges were bolted. The pin flange and the choke flange both show similar results with $\mathrm{S} 11$ below $-20 \mathrm{~dB}$ up to $315 \mathrm{GHz}$. The case when there was nothing between the straight rectangular waveguide and the measurement flanges, and no gap, shows the transmission (S21), $0.4 d B$ below the pin flange and choke measurements, which shows that even with controlled mounting, the standard flange leaks more compared to the modified prototypes. That, even when they have gaps of $56 \mu \mathrm{m}$.

F. Comparison of the pin flanges with standard flanges and choke flanges for the application of measuring on a resonator

Measurement results of the resonator connected to the pin-flange adapter at each side (solid line), together with simulated data for a standard flange ideally connected to the resonator (dashed line) are shown in Fig. 20. As it can be seen, the resonator shows clear resonances, even with an air gap of $56 \mu \mathrm{m}$ present between the flanges and the chip. 


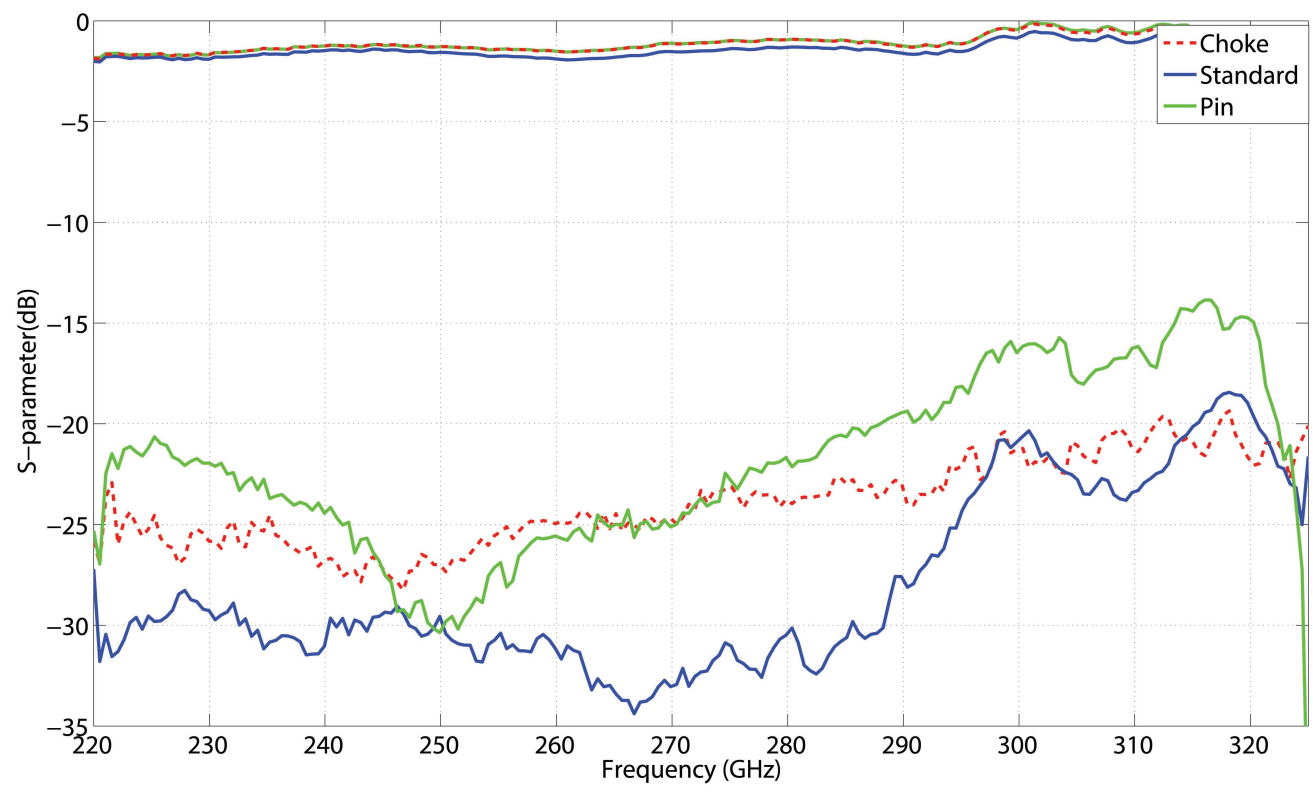

Figure 19: Measurements on a straight rectangular waveguide with a length of $25.425 \mathrm{~mm}$ with a standard (blue solid line) connection, with a choke flange on each side (red dashed line) and with a pin flange on each side (green solid line)

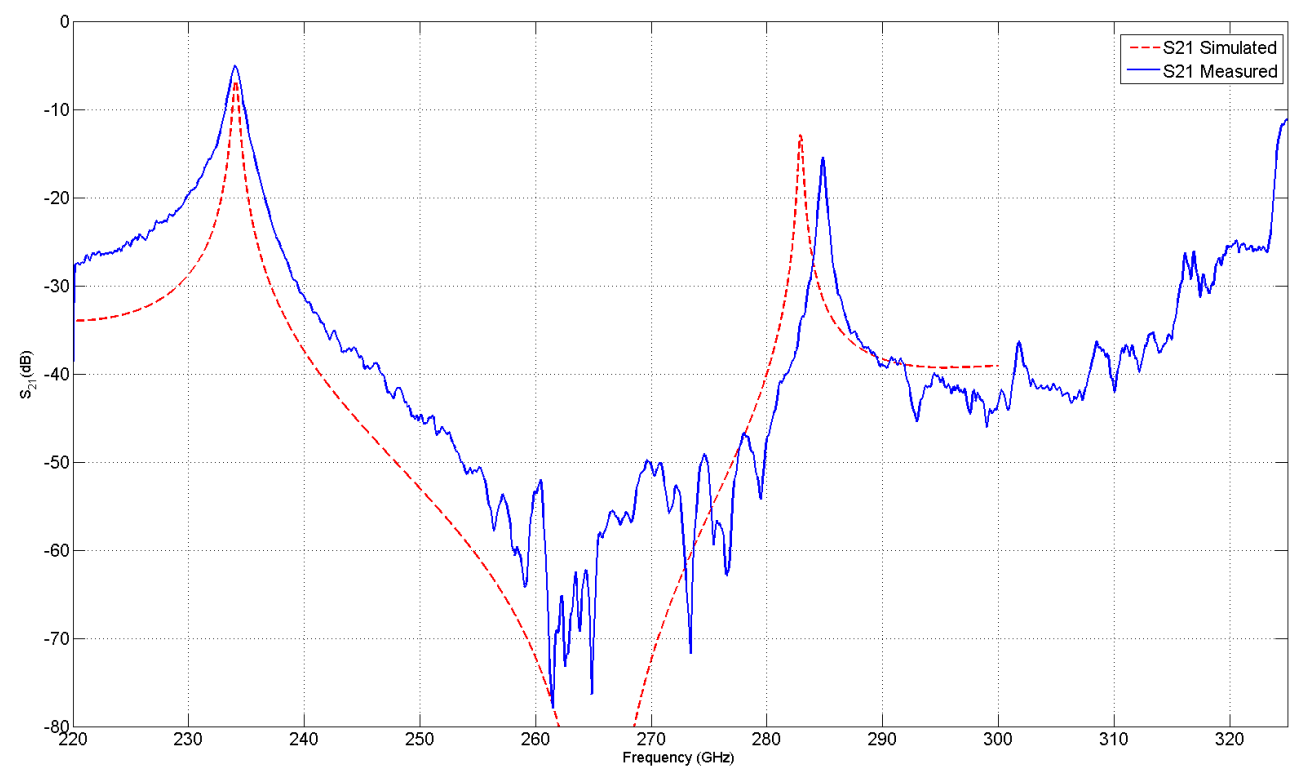

Figure 20: Solid line: Measurement of a single-pin-row resonator with the pin-flange adapter. Dashed line: Simulated data with standard flanges connected perfectly to the resonator.

Fig. 21 shows measurement results of the same resonator measured with three kinds of flanges: pin flanges, choke flanges and standard flanges. The results agree acceptably for the 
three cases. The pin flange performs as well as the standard flange over the entire intended frequency range even though there is a gap between the pin flange and the measured resonator, which, for a regular flange, would be very detrimental to the system's performance. This shows the ability of the pin flange to achieve a more robust measurement setup, insensitive to small gaps.

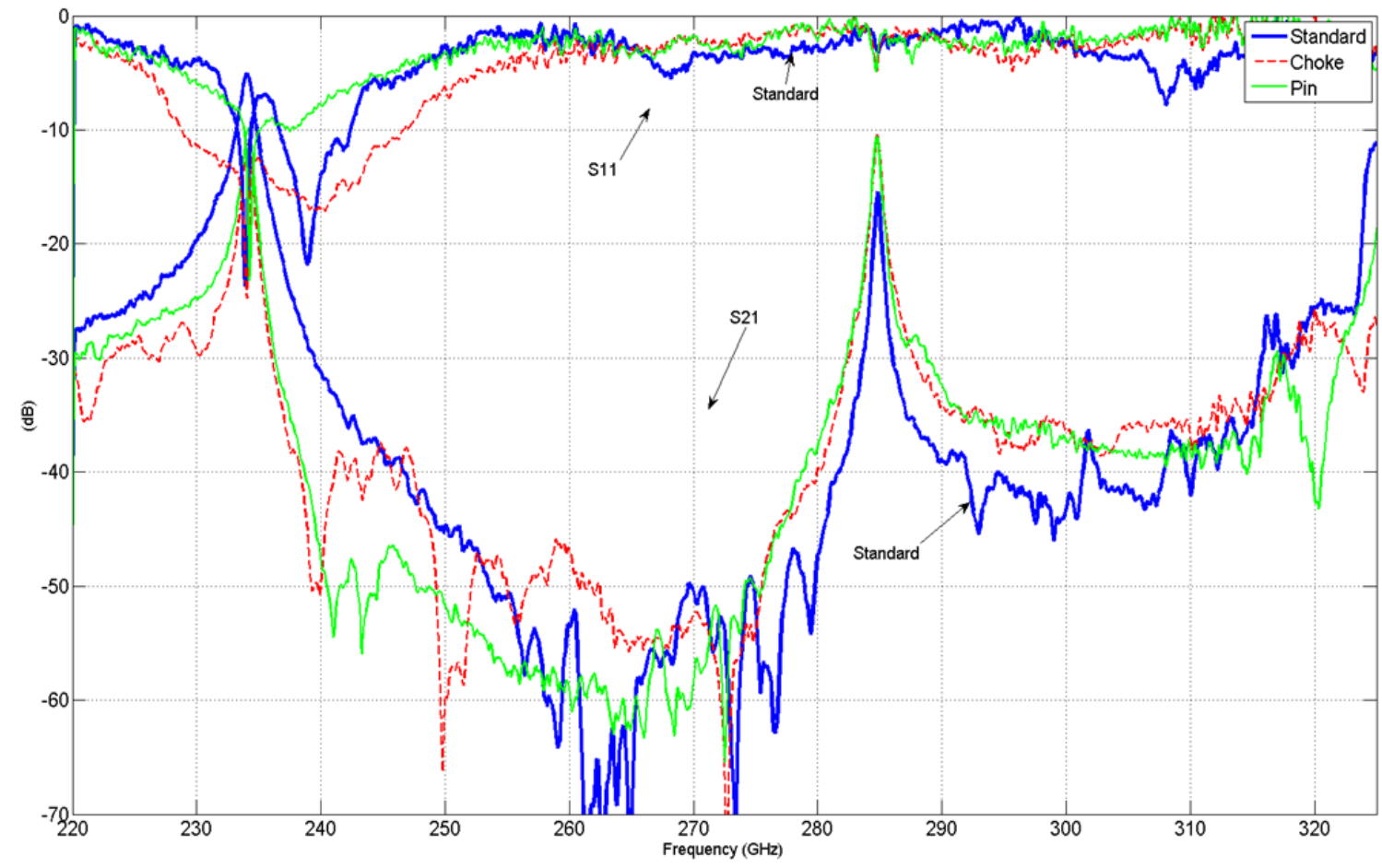

Figure 21: Comparisons between the standard flanges (blue solid line), the choke flanges (red dashed line) and the pin flanges (green thin line) for measuring a resonator.

\section{VI - Conclusion}

The first micromachined contactless double sided pin-flange adapter has been demonstrated. The pin-flange adapter presented in this paper also has the benefit of being easy to retrofit on an existing measurement equipment and just as easy to remove. Therefore, one can keep the existing measurement setup and just add the pin-flange adapter as an accessory to increase the tolerance to gaps. The pin flange and the choke flange show robust measurements, displaying similar behaviour when mounted with and without fixing screws with a gap of $56 \mu \mathrm{m}$ compared to the standard waveguide connection that had no gap. The tolerance study shows 
that the micromachined pin flange can work with gaps of at least up to $60 \mu \mathrm{m}$, with S11 below $-15 d B$ from $240-325 G H z$. The tolerance study also shows that the optimal gap for the micromachined pin flange in this case is $40 \mu m$, with $\mathrm{S} 11$ below $-20 d B$ from $240-325 \mathrm{GHz}$. Both the milled and micromachined pin flange show a return loss below $-20 \mathrm{~dB}$ with a $50 \mu \mathrm{m}$ gap for an equally wide frequency range but slightly shifted in frequency. The two different pin flanges and the choke flange show a better return loss than for the standard waveguide disc with a $50 \mu \mathrm{m}$ gap. When the flanges are applied to a standard rectangular waveguide with a length of $25.425 \mathrm{~mm}$, it is clear that the S21 for the choke and pin flange with a $56 \mu \mathrm{m}$ gap, has a better performance than the standard waveguide connection that has been bolted with no intended gap. The flanges have also been tested successfully on a ridge-gap waveguide resonator, showcasing an application of the flanges. The micromachined pin flange has been mounted and dismounted and measured more than 40 times during measurements, without any observable damage. Thus we conclude that the micromachined pin flange is also mechanically quite robust.

\section{VII - Acknowledgement}

The authors would like to acknowledge the Swedish Research Council VR, a project within the VINNOVA funded Chase antenna systems VINN excellence center at Chalmers and the Chalmers production area of advanced science for funding of the reported work. The authors are also grateful to the nanofabrication laboratory at Chalmers University of Technology for their assistance in the fabrication process and to Carl-Magnus Kihlman (Chalmers University of Technology) who milled the first prototypes.

\section{References}

[1] W. R. McGrath, C. Walker, M. Yap, and Y.-C. Tai, "Silicon micromachined waveguides for millimeter-wave and submillimeter-wave frequencies," IEEE Microwave And Guided Wave Letters, vol. 3, no. 3, pp. 61-63, 1993.

[2] M. Yap, Y.-C. Tai, W. R. McGrath, and C. Walker, "Silicon Micromachined Waveguides 
For Millimeter And Submillemeter Wavelengths," in Third International Symposium on Space Terahertz Technolog, (Ann Arbor), pp. 316-323, 1992.

[3] C. Jung, C. Lee, B. Thomas, G. Chattopadhyay, A. Peralta, R. Lin, J. Gill, and I. Mehdi, "Silicon micromachining technology for $\mathrm{THz}$ applications," in 35th International Conference on Infrared Millimeter and Terahertz Waves (IRMMW-THz), (Rome), pp. 1-3, 2010.

[4] P. Kirby, D. Pukala, H. Manohara, I. Mehdi, and J. Papapolymerou, "Characterization of micromachined silicon rectangular waveguide at $400 \mathrm{GHz}$,' IEEE Microwave and Wireless Components Letters, vol. 16, no. 6, 2006.

[5] X. Shang, M. Ke, Y. Wang, M. J. Lancaster, and S. Member, "WR-3 Band Waveguides and Filters Fabricated Using SU8 Photoresist Micromachining Technology," vol. 2, no. 6, pp. 629-637, 2012.

[6] T. Skaik, Y. Wang, M. Ke, S. Qian, and M. Lancaster, "A Micromachined WR-3 Waveguide with Embedded Bends for Direct Flange Connections," in Proceedings of the 40th European Microwave Conference, (Paris), pp. 1225-1228, 2010.

[7] F. Sammoura, Y.-C. Su, Y. Cai, C.-Y. Chi, B. Elamaran, L. Lin, and J.-C. Chiao, "Microfabricated plastic 95-GHz rectangular waveguide," in 18th IEEE International Conference on Micro Electro Mechanical Systems, MEMS, pp. 167-170, 2005.

[8] J. Hirokawa and M. Ando, "Single-layer feed waveguide consisting of posts for plane TEM wave excitation in parallel plates," IEEE Transactions on Antennas and Propagation, vol. 46, 1998.

[9] K. Wu, D. Deslandes, and Y. Cassivi, "The substrate integrated circuits - a new concept for high-frequency electronics and optoelectronics," 6th International Conference on Telecommunications in Modern Satellite Cable and Broadcasting Service 2003 TELSIKS 2003, vol. 1, pp. P-III-P-X, 2003. 
[10] P.-S. Kildal, E. Alfonso, A. Valero-Nogueira, and E. Rajo-Iglesias, "Local metamaterialbased waveguides in gaps between parallel metal plates," IEEE Antennas and Wireless Propagation letters (AWPL), vol. 8, pp. 84-87, 2009.

[11] P.-S. Kildal, “Three metamaterial-based gap waveguides between parallel metal plates for mm/submm waves," in 3rd European Conference on Antennas and Propagation (EuCAP 2009), vol. 8, (Berlin, Germany), pp. 84-87, 2009.

[12] P.-S. Kildal, A. U. Zaman, E. Rajo-Iglesias, E. Alfonso, and A. Valero-Nogueira, "Design and experimental verification of ridge gap waveguide in bed of nails for parallel plate mode suppression," IET Microwaves, Antennas \& Propagation, vol. 5, no. 3, pp. 262$270,2011$.

[13] E. Rajo-Iglesias, A. U. Zaman, and P.-S. Kildal, "Parallel plate cavity mode suppression in microstrip circuit packages using a lid of nails," IEEE Microwave and Wireless Components Letters, vol. 20, no. 1, pp. 31-33, 2009.

[14] A. Algaba-Brazález, A. U. Zaman, and P.-S. Kildal, "Improved microstrip filters using PMC packaging by lid of nails," IEEE Transactions on Components, Packaging and Manufacturing Technology, vol. 2, no. 7, pp. 1075-1084, 2012.

[15] A. U. Zaman, P.-S. Kildal, and A. A. Kishk, "Narrow-Band Microwave Filter Using HighQ Groove Gap Waveguide Resonators With Manufacturing Flexibility and No Sidewalls," IEEE Transactions on Components, Packaging and Manufacturing Technology, vol. 2, pp. 1882-1889, Nov. 2012.

[16] A. Zaman, M. Alexanderson, T. Vukusic, and P.-S. Kildal, "Gap Waveguide PMC Packaging for Improved Isolation of Circuit Components in High-Frequency Microwave Modules," IEEE Transactions on Components, Packaging and Manufacturing Technology, Nov. 2013.

[17] A. U. Zaman and P.-S. Kildal, "Wide-band Slot Antenna Arrays with Single- layer Corporate-Feed Network in Ridge Gap Waveguide Technology," Submitted to IEEE Transactions on Antennas and Propagation, 2013. 
[18] S. Rahiminejad, A. Algaba-Brazález, H. Raza, E. Pucci, S. Haasl, P.-S. Kildal, and P. Enoksson, "100 GHZ SOI GAP WAVEGUIDES," in Transducers 2013, The 17th International Conference on Solid-State Sensors, Actuators and Microsystems, pp. 10$11,2013$.

[19] S. Rahiminejad, H. Raza, A. U. Zaman, S. Haasl, P. Enoksson, and P.-S. Kildal, "Micromachined Gap Waveguides for $100 \mathrm{GHz}$ Applications," in 7th European Conference on Antennas and Propagation (EUCAP 2013), no. Eucap, pp. 1935-1938, 2013.

[20] S. Rahiminejad, A. U. Zaman, E. Pucci, H. Raza, V. Vassilev, S. Haasl, P. Lundgren, P.-S. Kildal, and P. Enoksson, "Micromachined ridge gap waveguide and resonator for millimeter-wave applications," Sensors and Actuators A: Physical, vol. 186, pp. 264-269, Oct. 2012.

[21] M. G. Silveirinha, C. A. Fernandes, and J. R. Costa, "Electromagnetic characterization of textured surfaces formed by metallic pins," IEEE Transactions on Antennas and Propagation, vol. 56, pp. 405-415, Feb. 2008.

[22] E. Rajo-Iglesias and P.-S. Kildal, "Numerical studies of bandwidth of parallel-plate cutoff realised by a bed of nails, corrugations and mushroom-type electromagnetic bandgap for use in gap waveguides," IET Microwaves, Antennas \& Propagation, vol. 5, no. 3, p. 282, 2011.

[23] E. Pucci and P.-S. Kildal, "Contactless Non-Leaking Waveguide Flange Realized by Bed of Nails for Millimeter Wave Applications," in 6th European Conference on Antennas and Propagation (EUCAP), pp. 3533-3536, 2012.

[24] D. M Pozar, “Microwave Engineering, 3rd,” JOHN WILEY SONS INC, 2005.

[25] J. Hesler, "A photonic crystal joint (PCJ) for metal waveguides," in 2001 IEEE MTT-S International Microwave Sympsoium Digest (Cat. No.01CH37157), vol. 2, pp. 783-786, 2001. 
[26] E. Pucci, A. U. Zaman, E. Rajo-Iglesias, P.-S. Kildal, and A. Kishk, "Study of Q-factors of ridge and groove gap waveguide resonators," IET Microwaves, Antennas \& Propagation, vol. 7, pp. 900-908, Aug. 2013.

[27] X. Shang, M. J. Lancaster, M. Ke, and Y. Wang, "Measurements of micromachined submillimeter waveguide circuits," 2010 76th ARFTG Microwave Measurement Conference, pp. 1-4, Nov. 2010.

[28] S. Rahiminejad, E. Pucci, S. Haasl, and P. Enoksson, "Contactless pin-flange adapter for high-frequency measurements," in 23de Micromechanics and Microsystems Europe Conference, 2012.

[29] "The direct industry website." http://www.directindustry.com/tab/micro-mill.html. Accessed: 2014-04-15. 